\title{
Socialization of economy in the conditions of continuous wellbeing's innovative model
}

\author{
Anastasiya Zhavoronok $^{1}$, Magerram Gasanov ${ }^{1 \mathrm{a}}$, Sergey Zhironkin ${ }^{1}$ \\ ${ }^{1}$ Tomsk Polytechnic University, 634050 Lenin av., 30, Tomsk, Russia
}

\begin{abstract}
Socialization of economy is connected with a basic change of the person's position in production and her or his wellbeing in society. Radical activation of the human capital appears in creative participation of the worker in production and promotes growth of continuous wellbeing and fully reveals its intellectual, moral, creative qualities. In this case the reproduction of the worker appears as all-round development of the personality; as expanded reproduction expressed in equipment by her or his knowledge, growth of her or his creative abilities and increase of moral. The solution of the technological freedom's problem of the worker from a status of an appendage of an extensively developed machine device consists in a deep quality leap in development of productive forces on the basis of achievements of scientific and technical progress and formation of a new model of economic wellbeing of the person. There is an approach to the analysis of technologies socialization in innovative economy in the process of work, in which the person and the equipment are in indissoluble functional unity. This approach allows investigating regularities of development of technologies together with the content of work, which is qualitatively transformed and obtains key characteristics, such as humanization, serviceability and socialization.
\end{abstract}

\section{Introduction}

Socialization of the reproduction process, with the matter of a specific essential feature of the innovative model of economic growth under conditions of information technology revolution of the modern stage, is inseparably connected with a radical change of a human position in the production process. Radical intensification of human capital as a factor of the production process under conditions of innovative scientific and technical development is manifested in the creative participation of a worker in the production process, where worker serves as the main productive force and the subject of institutional relations, and in the social sphere, where the employee undergoes transformation of social relations, formation and the development of personality. The level of socialization of national production is determined by the aspect of an employee highlighted in a number of productive powers such as personal development; fully disclosed intellectual, moral, creative qualities; possession of the production process and becoming the purpose of production itself (not a production agent) [1].

Reproduction of a worker itself stands as a comprehensive development of the individual, as expanded reproduction in the sense of knowledge possession, growth of creative abilities and morality increase of a worker. Innovative scientific and technical

\footnotetext{
a Corresponding author: hursud1@yandex.ru
}

development, in most advanced market economies, brings production to a stage where socialization becomes its main feature, since the social progress is defined by the development of personality. The category of «Socialization of the economy» was actively used in the early 20 th century [2].

\section{Materials and methods}

In Western economic literature, the problem of socialization in the context of the development of the productive forces and production methods have been considered for a long time [3]. The idea of «socialization of the economy» is most fully presented in J. Galbrate works [4]. He proceeds from the principle that the set of institutional economic relations should not change from formation, but it should change constantly as the productive powers of society.

J. M. Keynes focused on the socialization of economic life, including investment, which is perceived as a way to state socialism [5]. Herewith he assumed a gradual transition: «In addition, the necessary measures of socialization can be introduced gradually, without breaking the established traditions of society». Y. Schumpeter also gives a lot of attention to the socialization. He titled it «an objective historical movement trend to socialism» [6]. 


\section{Results and discussion}

The development of the productive powers of the entire economic system under new conditions of information technology (IT) revolution evolves its social direction with the inevitable necessity. In the developed countries IT revolution proves more practically the link between economic and social problems and the inability to solve the former excluding the latter [7].

A qualitatively new level of productive powers and its distinctive features emerge through the current status of the advanced fields of science, technology and production. On the one hand, it is characterized by opening the possibility to transfer the management process of the material production system to technical devices (machines), and, on the other hand, by changing the way of attitude itself to nature as habitat, the main condition of production. With the extensive application of information, communication and radically new technologies of a new industrial management brings the social side of labor to the fore.

Technological quittance of the workers and their elimination from production are not new subjects. Marx, following Hegel, pointed out that a person, with the use of the machines, is constantly «eliminated» from the direct production; her or his human, more precisely animal force in production more often replaced by the natural forces [8].

The need for technological quittance of the workers is commonly determined by the fact that the main stage of the world IT revolution has approached. It is a production stage, which includes practical implementation of the newest automation production technologies on the basis of computerization, robotics, micro process application.

However, in the socio-economic literature, this topic is discussed mainly by changes in the matter, industrialization and intellectualization of labor [9]. The most interesting in this respect is, in our opinion, the work of N.V. Markov [10].

Still, there is no necessary and explicit emphasis on the fact that the indicated processes occur during an extensive type of economic growth too.

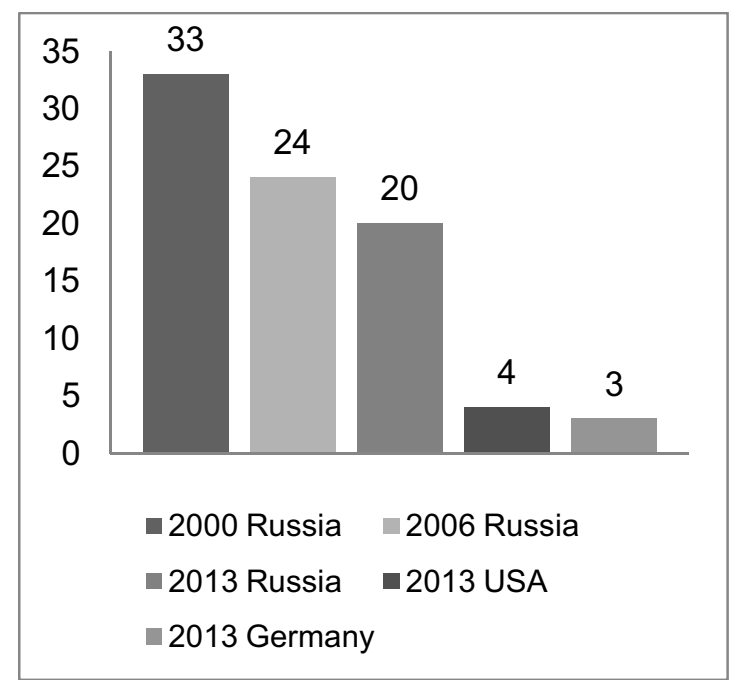

Fig. 1. The estimated proportion of the population without income consideration, \%

All previous technological modes of production (an instrumental mode and a machine mode, which is the current one) based on the technological connection of a person and the instruments of labor by their «close» direct connection. At all stages of the development of technology and the productive powers, prior to automation, a person was strictly included in the technological process as an operator of a certain technological function. A productive process has been performed only while a person himself/herself remained its direct participant. In the crafts sector there was a craftsman with a set of multipurpose tools; in the manufactory sector there was a worker, who, with the help of specialized tools, manually performed one partial operation; in the machine mode of production again there was and there is a person, who supplements the machine by performing partial, so-called machine functions [11]. Even in the manufactory sector, the tool plays the role of a servant; in the machine mode of production, subordination of a worker to the machine is constant.

Technological subordination of a worker to the machine is completed by complex mechanization and partial automation, becoming the technological essence of the reproduction process of extensive type. A completion process divides human capabilities in two aspects: physical labor (rigid functions of the physical and spiritual production potencies) and scientific and intellectual labor (as the concentration of creative spiritual production potencies).

A worker becomes a living appendage of an extensively developed machine system. Machine, as the embodied power of knowledge, becomes the dominant element of the productive powers and overmasters a person in the process of labor. The material element of the productive powers overmasters the human productive power in the direct act of production.

The functional matter of labor is determined by the type of equipment and technology, subjects of labor (the degree of mechanization and automation of production), that have direct technological communication with the person in the process of labor.

The matter of labor is characterized by a set of those technological functions which a person performs in the process of labor in combination with technique. These functions may prescribe the execution of creative operations requiring the effort of intellectual abilities, as well as execution of rigid operations such as physical and intellectual monotonous works.

A person as a source of development of the large machine production at the same time appeared to be its obstacle. It is due to the fact that this method of the production mode to a greater extent than any other modes of production subordinates, defalcates, and overdrives technologically such subjective productive power as a person, bringing her or him down to a level of simple labor power [12].

Solving the problem of technological liberation of a collective worker from the condition of the appendage of 
an extensively developed machine device is seen in the deep quantum leap in the development of productive powers on the basis of scientific and technical progress achievements and in the formation of a new model of economic growth. This is a deep social significance of scientific and technical progress at the innovatively capacious stage of intensive economic growth in the field of highly developed market relations.

The functional purpose of the technology and human, on the basis of materialized achievements in scientific and technical progress under conditions of formation of the innovatively capacious stage of intensive economic growth, is fundamentally changed and radically transformed. The position of a person and her or his role in the production, matter and character of her/his work, all physical and intellectual activities become rather diverse.

Any changes in the instruments and subjects of labor acquire the deep social and historical meaning only when measured by the human scale, where «the whole human personality and its capabilities» principle [13, 14] elevates a person to the new social height.

With new technology it is possible to extend consumer practices. Consumers, having full knowledge of market conditions, tend to choose well-known brands, containing association and positive representations about goods and services.

Indeed, the growth of people needs is permanently observed. That serves as incentive for expanding the range and improving the quality of produced goods and services. First of all there is the rationalization of consumer behavior. The theory of a consumer choice implies that the consumer seeks to maximize the utility, while a consumer's balance is being achieved. But wide access to information today gives the consumer much more flexibility, and utility maximization occurs at a higher level of its satisfaction. The market becomes much more consumer-oriented than 30-50 years ago.

We distinguished three types of a modern consumer:

1) A wide-scale and educated consumer (qualified and acquainted with the needs of high-quality goods and services. This consumer distances himself (herself) from the cheap goods and services. Minimization of the consumer's infantilism requires an organized system of consumer training.

2) A mass cultural consumer, which is able to choose the necessary goods and services from the great mass of a variety of standard products and services. If the consumer distinguishes new products and services in this mass, he (she) really distinguishes the necessary quality. It is formed by the dynamic domestic market and by demand within innovation-oriented economy. This has an impact on the results of business activity in all sectors of the economy, brings the interests of consumers, their economic behavior to the first place. The main characteristic of such economic relations is the growing role of the individual and his (her) needs.

3) A universal consumer is a person who understands the enormous value of innovative, unique products and services.

Culture and art materials take the form of a product, filling the free time of a consumer. Awakening interest of people to the arts, cultural values, concepts, ideas, brands, trademarks are the part of the formation process of an information society. Pieces of art from a market point of view become a part of everyday life. High interest is the professional attitude of the consumer, able to choose and to make effective decisions.

Innovative development requires functioning of intellectualized and personalized consuming power. This process of active work and individual social development forms a giant massif of intellectual power. The combination of intellectual and aestheticized purchasing power characterizes a creative individual. She/he is capable of the most complex effective solutions (consumer innovation). Under the new conditions the formation of innovation ideas is associated with the concept of consumer innovation which changes the concept of the organization of innovation, which is a key concept of society. In accordance with the concept of consumer innovation the novelty is a set of properties that characterizes the radical nature of the object changes, based on the estimation of these changes by a consumer that gives him (her) the right to treat them like the new ones.

Thus, creativity is becoming a major feature, for both producers and consumers, based on which the innovations are born. Employees of firms and consumers themselves can be its generator. Under the new conditions the producers adapt production to customer's requirements. This process is known as the "mass customization". Universal consumers prefer innovative products and services. This is a distinctive feature of the universal consumer. Creativity is the source of enormous energy for the development of innovative technologies. Universal consumers always seek to be the first buyers of innovative products and services. They create a demand for innovation. Formation of a universal consumer is important in a macro-economic aspect, as well as for micro-economy.

The macroeconomic aspect of this process is linked to the socially oriented market economy, to the strengthening of a consumer market position and to the movement of the economy in an innovative conversion direction. The microeconomic aspect is interesting from a business point of view, since it is connected with the possession of competitive advantages of innovative products and services on the market.

In the coordinates of innovative development the exchange of economic goods between individuals is a communion of these individuals in the knowledge, abilities and skills that are embodied and objectified in these goods. Because of their ideal character, knowledge and skills do not disappear in the acts of goods consumption and pass to the consumers and are transferred to the new values generated by these consumers. In the process of sharing it expands the circle of persons who can obtain more new knowledge and skills.

An approach to the analysis of equipment and technology through the process of labor, in which a person and technology exist in inseparable functional unity, has important methodological significance. It allows scientific revealing of the development of the 
technology pattern, nodes, major historical stages of the development and matter of labor qualitatively, which is qualitatively transformed depending on the level and the state of the equipment. Qualitative transformations in technology, emerging in the course of scientific and technological progress, mean the beginning of the new large historical period in the development of the productive powers. It is notable that the technological essence of scientific and technical progress stands as an automated technological mode of production. Its essence is the following: instead of a working machine there is a technical device that qualitatively converts the functional matter of labor and the whole technological mode of production, thereby, becoming the technical basis for the socialization of national production. As a rule, under conditions of a complex of the automated production, a technological process goes on independently, without direct inclusion of a person. A worker only provides an objective of production and a corresponding hardware (maintenance) program, and if necessary, carries out its sub alignment and control.

Different functional capabilities act as a qualitative watershed between mechanization and automation, between the existing traditional working machine (for example, a common lathe) and a forming (or existing) automatic device (for example, a lathe with numerical program control). In other words, equipment, which implemented a new "function of labor» and is compared to the working machine, can be considered as the «radically new» equipment. In the process of production, or more precisely, in the real labor process it is necessary to ensure that certain operations, previously performed by a person, were transferred to a technical device and implemented by means of it.

The essence of qualitative changes in modern productive technology is presented in three aspects: the transition to the use of non-mechanical principles in the production; the penetration in depth of a substance; the involvement of «molecular, atomic and subatomic levels of the substance». This leads to the development of socalled basic technologies, which will constitute the material basis of the modern economy.

The use of innovative technological principles is highly effective in creating flexible automated production works. With the help of these principles one technological process could combine mechanical processing of details with automatic welding, thermal hardening, changing of the crystal structure of matter, automatic control, automatic change of a processing rate and etc. High technological and social efficiency is achieved due to these aspects.

\section{Conclusion}

The distinctive feature of the newest production technologies is that they expand the scope of nonequipment machinery on the basis of its synthesis with technology. The mechanical impact on a subject of labor is replaced by using physical, chemical, biological (biotechnology), and other properties of matter and the organism. All these facts concern a growing process of replacement of extensively developed instruments of labor through the application of natural resources' processes on the basis of the newest technologies.

Concluding the essence analysis of the innovative instruments of labor, deep qualitative transformations in the production and intensive type of economic growth, it is necessary to emphasize that under the influence of these processes a new, adequate to the intensive type of economic growth, technological mode of production is formed.

The use of automated equipment, which consists not only of the developed machine device of the fourth level, but also of technical systems including non-equipment machinery and technology applied to the subjects of labor in non-mechanical ways, is impossible for the traditional workers. This automated equipment can only be used by highly qualified workers of intellectual work.

These workers are impossible to train without social conversion of an economic and household sector along with the automation "won't do». Consequently, the intensification of innovative processes is deprived of its material basis.

In conclusion, the analysis made in this paper allows us to mark the following: firstly, the criterion of a qualitatively new state of the equipment is its impact on the qualitative changes in the functions of the matter of labor; secondly, automation cannot be reduced only to this functional aspect. In addition to the automation of functions of labor, it provides four main directions, leading to technological release of the worker from the condition of the appendage of traditional machines. Thirdly, in order to be qualitatively new and to provide technological release of the worker, automated equipment should be partially or fully released from the structure of the traditional equipment.

\section{Acknowledgment}

This work was performed by the authors in collaboration with Tomsk Polytechnic University within the project «Evaluation and enhancement of social, economic and emotional wellbeing of older adults» under Agreement No.14.Z50.31.0029.

\section{References}

1. E.A. Gasanov, M.A. Gasanov, MESI (1993)

2. V. Chernov, (1997)

3. K. Eklund, Economics (1989)

4. J.K. Galbraith, (1969)

5. J. M. Kanes, (1978)

6. Y. Schumpeter, Economics (1995)

7. A.G. Voitov, Fundamental economic theory (2000)

8. K. Marx, F. Engels, Economic manuscript 18611863

9. E. Vilkhovchenko, Global economy and international relations, 9, (1997)

10. N.V. Markov, Znaniye (1979)

11. J. D. Bernal, (1956)

12. A. Agg, Progress (1984)

13. A. Pechei, Progress (1985) 
14. M.A Gasanov, Zh.A Ermushko, A.V. Zhavoronok, EpSBS, 8, (2016) 